New Book Received *

\title{
Tropical Forestry Handbook, Second Edition. Edited by Laslo Pancel and Michael Köhl, Springer-Verlag, 2016; 3633 pages, 4 Volumes. Price: \$2,500.00, ISBN 978-3-642-54600-6
}

Shu-Kun Lin

MDPI AG, St. Alban-Anlage 66, 4052 Basel, Switzerland; lin@mdpi.com

Received: 22 September 2016; Accepted: 18 October 2016; Published: 20 October 2016

The Tropical Forestry Handbook [1] has been prepared by professionals that are dedicated to the protection and the sustainable management of tropical forests. They want to make their expertise available for a wide audience. Their contributions provide valuable insight in sustainable tropical forest management. It is our hope, that the Tropical Forestry Handbook will become a helpful tool for mastering the current and future challenges of tropical forests. It is our hope that this book acquires a liking for young people especially. And it is our hope that readers join us and will not be released ever again from the miscellany, uniqueness and fascination of tropical forests.

\section{Table of Contents}

Introduction to Tropical Forestry and to This Handbook

Tropical Forest Resources-Facts and Tables

International Processes-Framework conditions for Tropical Forestry

Climatology and Meteorology considering Climate Change

Identification of Tree Species in the Tropics

Tropical Forest Ecology

Scope and Extent of Wood Biology

Remote Sensing of tropical Forestry Resources

Forest Resources Assessment

Genetics and Tropical Forests

Forest Seeds

Forestry Nursery Management

Plant Nutrition in Tropical Forestry

Species Selection in Tropical Forestry

Basic Outline of tree plantations in the Tropics

Tropical Silviculture

Mangrove Forests and their management

Forestry Management

Land Evaluation and Forestry Management

Watershed Management

Range Management

Agroforestry: essential for sustainable and climate-smart land use?

Community Forestry

Wildlife Management

Nature Conservation 
- Forest Road Engineering

- Forestry Harvesting Operations

- Pest Management

- Fire Management in Tropical Forests

- From Lifelines to Livelihoods: Non-timber forest products into the 21st century

- Grading Forestry Products

- Forestry Economics

- Compensation Payments, PES, CDM, REDD in Forestry

- Forestry Project Management

- Forest Markets

- Ergonomics / Forestry Labor

- Indigenous People and Forests

. Forestry Extension

- Tropical Forest Policy and Legislation

- Forest Rights of Target Groups

- Forest Crime in the Tropics

- Introduction to forest certification schemes

- Changing Trends of Forestry Research Demand

- Research Areas in Tropical Forestry

Index

* Editor's Note:

The brief summary and the contents of the books are reported as provided by the author or the publishers. Authors and publishers are encouraged to send review copies of their recent books of potential interest to readers of Forests to the Publisher [Dr. Shu-Kun Lin, Multidisciplinary Digital Publishing Institute (MDPI), St. Alban-Anlage 66, 4052 Basel, Switzerland. Tel.: +41-61-683-77-34; Fax: +41-61-302-89-18, E-Mail: lin@mdpi.com]. Some books will be offered to the scholarly community for the purpose of preparing full-length reviews.

\section{Note}

1. The website for this book is: http://www.springer.com/us/book/9783642546006.

(c) 2016 by the author; licensee MDPI, Basel, Switzerland. This article is an open access article distributed under the terms and conditions of the Creative Commons Attribution (CC-BY) license (http://creativecommons.org/licenses/by/4.0/). 